\title{
REBOBINANDO O MOTOR: UM CASO SOBRE AMBIDESTRIA ORGANIZACIONAL
}

\author{
REWINDING THE MOTOR: A CASE OF ORGANIZATIONAL AMBIDEXTERITY
}

\author{
Recebido em 09.03.2017. Aprovado em 19.06.2017 \\ Avaliado pelo sistema double blind review \\ DOI: http://dx.doi.org/10.12712/rpca.v11i3.739
}

\section{Aline Jansen}

aline_jansen@yahoo.com.br

Universidade Federal de Pelotas (UFPel), Pelotas/RS, BRASIL

\section{Elvis Silveira Martins}

elvis.professor@gmail.com

Universidade Federal de Pelotas (UFPel), Pelotas/RS, BRASIL

\section{Resumo}

Com a intensificação da competição, as organizações sentem a necessidade de utilizar estratégias com eficácia comprovada e contemporânea. Neste sentido, observa-se a ambidestria, explorando as novas possibilidades e explotando as antigas certezas. Assim, por acreditar-se que a ampliação dos debates sobre a ambidestria é contributivo ao desenvolvimento da temática, este caso para ensino visa apresentar os conceitos ligados à mesma, ilustrando-os através da descrição do percurso por qual passou o personagem principal da história. O caso inicia na trajetória acadêmica/pessoal de José, narrando também as suas experiências profissionais. $\mathrm{Na}$ sequencia, relata-se o processo de abertura do negócio especializado em uma marca multinacional de ferramentas elétricas e apontam-se os desafios que o personagem precisou enfrentar na formulação de suas estratégias, além de trazer alguns dilemas para reflexão e debate sobre a ambidestria e as dimensões exploração/ explotação à luz do contexto gerencial.

Palavras-chave: Estratégia Ambidestra. Exploração. Explotação.

\begin{abstract}
With the intensification of competition, organizations feel the need to use strategies with proven effectiveness and contemporary. In this sense, we identify the ambidexterity, that exploration new possibilities and exploitation old certainties. Thus, for believing that the expansion of discussions about ambidexterity is contributive to develop the theme, this case for education aims to introduce the concepts related to it, illustrating them through the course of the description by which it became the main character of the story. The case begins in Josés academic career and personal path also chronicling their professional experiences. Moreover, we report the process of opening the specialized business in a multinational brand of power tools and point to the challenges that the character had to face in formulating their strategies, as well as bring some dilemmas for reflection and debate on the ambidexterity and dimensions of exploration and exploitation in the managerial context.
\end{abstract}

Keywords: Ambidextrous Strategic. Exploration. Exploitation. 


\section{Introdução}

Com a intensificação da competição e aceleração das mudanças mercadológicas, as organizações sentem a necessidade de utilizar a ambidestria na sua estratégia organizacional, explorando as novas possibilidades que surgem e explotando as antigas certezas das quais elas já têm conhecimento avançado.

A ambidestria organizacional, sustentada na exploração (inovação) e explotação (aprimoramento) dos processos organizacionais, apresenta-se como uma ferramenta para a formulação de estratégias que procura otimizar os recursos internos, neutralizando (ou contornando) as ameaças impostas pelo ambiente e, com isto, gerando melhores resultados para as empresas. Como consequência do melhor desempenho, as organizações, também, habilitam-se a obter vantagem competitiva frente aos players do seu segmento.

Embora a teoria seminal tenha sido formulada há 42 anos com Duncan (1974) - com algumas das suas principais contribuições se sucedido com March em 1991 - e muitos testes, associações e conclusões já tenham sido assumidos, ainda assim pairam muitos questionamentos e inquietações nas agendas de pesquisa dos cientistas interessados na temática, principalmente aqueles direcionados às estratégias organizacionais. Talvez um dos principais questionamentos esteja direcionado a como gerenciar as ações de exploração e explotação das organizações de maneira sinérgica ou desbalanceada. Neste sentido, ressalta-se que a evidenciação de corrente teórica (eg. GUPTA; SMITH; SHALLEY, 2006; Ramachandran, 2012; SILVEIRA-MARTINS; ROSSETTO; AÑÃ̃A, 2014) que contrapõem o pensamento inicial, principalmente de March (1991), onde debatese que a ambidestria não necessariamente utiliza-se o balanceamento dos dois tipos de inovação, existindo a possibilidade de múltiplas combinações dos mesmos.

Diante deste contexto, acredita-se que ampliação dos debates sobre a ambidestria é contributivo ao desenvolvimento da temática, além de amplificar o suporte aos tomadores de decisões interessados na aplicação da ferramenta para a performance de suas organizações. Assim, apresenta-se o caso para ensino cujo objetivo reside na apresentação dos conceitos e debates relacionados à ambidestria a luz das tomadas de decisões (e angústias gerenciais) de um empresário do segmento de ferramentas elétricas, representante de uma multinacional reconhecida no mercado pela qualidade de seus produtos e serviços.
Desta maneira, no presente caso, descreve-se a história de José que, a partir de seus conhecimentos práticos, contatos e após trabalhar na oficina de seu pai, decidiu fundar o seu próprio negócio de prestação de serviços técnicos, mas com a particularidade de ser especializado em uma única marca conhecida internacionalmente. Como sua empresa é a única assistência técnica de ferramentas elétricas especializada somente nessa marca em todo o estado, observou-se que, ao mesmo tempo em que a estratégia foi inovadora, por outra ótica, ela foi incerta. Assim, José buscou implantar os componentes organizacionais básicos de uma empresa desse ramo, além da preocupação constante com manutenção da sua melhoria de forma permanente. Neste cenário, é possível perceber que a ambidestria está presente, implicitamente, em toda a trajetória do personagem e que as suas tomadas de decisões receberam crédito em função das estratégias ambidestras incorporadas por ele.

Com base neste contexto, o caso para ensino será apresentado considerando, inicialmente, a trajetória de vida profissional de José, bem como as suas interações com os demais personagens que trespassam e participam de sua jornada de pessoal/profissional. São apresentadas as angústias e tomadas de decisões sobre elas, nas diferentes fases da carreira do personagem. $\mathrm{Na}$ sequência, são apresentadas as notas de ensino, cujo objetivo é nortear docentes e profissionais na condução do caso, sendo, para tanto, incorporados nesta seção: objetivos educacionais; informações sobre os personagens; utilização recomendada; situaçãoproblema e sugestão de questões para discussão. $\mathrm{Na}$ penúltima seção é apresentado o arcabouço teórico que dará suporte à análise das situações que são apresentadas no caso para ensino. Por fim, na última seção, referenciam-se os teóricos utilizados para sustentar as argumentações que são apresentadas.

\section{Caso}

\section{0 aprendiz}

'Trabalhe e estude que tudo dará certo na vida'. Este era o conselho que Sr. Adão, empresário do setor de eletrotécnica do maior município da região sul do Rio Grande do Sul, recomendava ao seu filho José durante os almoços de domingo. Embora José já soubesse disso, sempre refletia sobre os ensinamentos de Sr. Adão, que costumeiramente, também, era repreendido por D. Adélia, sua esposa, com a fala: - 'Adão, toda 
vez a mesma coisa, deste jeito o José irá só estudar e trabalhar e não teremos netos'. Nestes momentos, José balançava a cabeça sorrindo e sem saber o que falar.

Seguindo na mesma linha do pai nos estudos, além de perceber que o mercado em que o Sr. Adão investira no passado era promissor e possuir o gosto pela área, José, com 14 anos, ingressou em uma Instituição Federal no curso de eletrotécnica. Nesta instituição, começou a fazer amigos e contatos profissionais com colegas e professores, alguns dos quais levaria para a vida toda. Durante as aulas, ele procurava prestar atenção em todos os detalhes e fazia uma projeção mental de como aplicar a matéria na prática. O curso possuía disciplinas de formação técnica - específicas para a proficiência da eletrotécnica - e disciplinas generalistas como: empreendedorismo, planejamento estratégico, marketing, recursos humanos e qualidade dos processos, que também interessavam o jovem estudante, pois o mesmo percebia que estas apresentam muitas oportunidades no segmento no qual pretendia dedicar-se.

De maneira concomitante com os estudos, José trabalhava na empresa do pai, especializada no conserto de eletrodomésticos, ferramentas elétricas e aparadores de grama, além de oferecer serviços de rebobinagem de motores elétricos. $\mathrm{Na}$ época, o negócio contava com 12 colaboradores e, embora José sempre tivesse demonstrado dedicação, atenção e cuidado nas atividades, ele executava apenas atividades básicas de assistência aos técnicos, além de alguns serviços rotineiros da empresa.

Durante as conversas no final do dia, D. Adélia perguntava ao Sr. Adão sobre como havia sido o dia do filho na empresa e sempre questionava o marido: - 'Porque você não permite que ele assuma outras funções, como a gestão da empresa? Um dia ele será o proprietário, não seria melhor ele começar a ser treinado?'. E, normalmente, a resposta do Sr. Adão era a mesma: - 'Primeiro, ainda tem muito tempo até ele assumir a empresa. Ou você acha que eu irei morrer logo?’ Após uma gargalhada, complementava: - 'Adélia, você já viu uma árvore crescer sem que as raízes estivessem bem presas a terra? É isto o que eu estou fazendo, ajudando as raízes de José se fixarem, mas na terra do aprendizado. Deste jeito ele está aprendendo todas as etapas de um negócio e trabalhando com todas as pessoas da empresa'. Nestes momentos, embora D. Adélia não concordasse muito com Sr. Adão, entendia que ele estava ajudando José e o melhor que tinha a fazer era esperar para que tudo ocorresse da melhor maneira possível.

Um dia, ao chegar ao curso, José notou que havia um cartaz de uma grande empresa local do ramo alimentício anunciando o processo seletivo para estágios na área de manutenção. Sem contar nada ao Sr. Adão, José participou do processo e foi selecionado. Após saber do resultado, José sentia um misto de alegria e preocupação. Alegria por ter sido selecionado e preocupação em como contar ao Sr. Adão. Resolveu procurar diretamente o pai no escritório, onde sentou na sua frente e contou exatamente o que havia acontecido. Após alguns segundos, , Sr. Adão perguntou: 'Porque você quer ir para outra empresa?' e, então, José respondeu: - 'Preciso de novas experiências. No curso de eletrotécnica o Professor da disciplina de recursos humanos frisou em muitas aulas que as empresas querem profissionais com conhecimento e que, para obter isso, era necessário ter experiências, entre outras coisas. Hoje eu possuo experiência na sua empresa, mas será que é o necessário? Além disso, com novos conhecimentos, poderei ajudar no negócio da família, melhorando e criando novos produtos e serviços'. Assim, sorrindo finalizou: - 'Quem sabe não será a consultoria mais barata que teremos?'. Neste momento, Sr. Adão abraçou e beijou filho na testa, após, fixando o olhar, disse: - 'Você está no caminho certo meu filho. Mas nunca esqueça, esta empresa é nossa! As portas estarão sempre abertas para você, ou melhor, as portas são suas!'.

Assim, na semana seguinte José ingressou na empresa como estagiário, atuando diretamente no setor de manutenção da indústria. Neste período, José aprendeu muitas técnicas e procedimentos que, até então, só lia em livros e no material das aulas. Verificou, também, que na empresa existia um processo de departamentalização, tal como ensinado na disciplina de qualidade. No entanto, havia outros dois departamentos que lhe chamavam mais a atenção: pesquisa e desenvolvimento - P\&D - e garantia, qualidade e melhoria dos processos - GQMP. No entender de José ambos os setores estavam diretamente correlacionados.

José sentia uma inquietação sobre a funcionalidade destes departamentos. Assim, durante um intervalo do curso, visualizou o Prof. Gean (docente da disciplina de qualidade dos processos) conversando com o Prof. Afonso (docente da disciplina de planejamento estratégico), e resolveu perguntar se a divisão dos departamentos estava correta. Após o questionamento, 
o Prof. Gean explicou: - 'A maneira como a empresa é departamentalizada é muito particular, pois na administração não existe um único caminho para o resultado'. E olhando para o Prof. Afonso complementou: - 'Afonso, poderia explicar melhor? Pois esta divisão pode estar atrelada ao planejamento estratégico da empresa'. Afonso, então, acrescentou: - 'Mais do que isto, me parece que está definido diretamente na estratégia da empresa. $\mathrm{O}$ nome disto é ambidestria organizacional. A empresa busca criar novos produtos e serviços, por isto o departamento P\&D e, ao mesmo tempo, visa aperfeiçoar o que já foi criado, logo, necessita do departamento GQMP. Ambos os movimentos, quando concomitantes, são frutos de uma estratégia ambidestra. Hoje em dia isto está sendo muito utilizado nas empresas e tem gerado bons resultados'.

José, muito satisfeito com aquela explicação, agradeceu a aula no corredor e disse que iria pesquisar mais sobre a estratégia ambidestra. Então, o Prof. Afonso resolveu ajudá-lo: - 'Amanhã deixarei alguns materiais sobre ambidestria para que você leia, se ficar com alguma dúvida, por favor, me procure'. Após, o Prof. Gean complementou: - 'Bem, pelo visto, você está interessado mesmo. Então, passe no final da tarde para pegar o material do Afonso, pois assim terei tempo de selecionar alguns livros sobre departamentalização que irão te ajudar e deixarei junto com os dele'. José agradeceu novamente a ajuda dos professores e dirigiuse para a sua sala de aula. Naquela noite, ao retornar para casa, teve a certeza que participar da seleção para o estágio havia sido uma tomada de decisão certa, por conta do que estava aprendendo.

Como havia sido combinado com os professores, José passou na Instituição e retirou o material sobre estratégia organizacional e métodos e, com eles, encontrou um bilhete que dizia: "Quanto mais eu estudo, mais sorte eu tenho. Nunca se esqueça dessa frase. Bons estudos! Prof. Afonso e Prof. Gean". A partir deste dia, tudo o que José lia pesquisava se estava sendo praticado na empresa onde estava estagiando. Quando não encontrava e existia a oportunidade, comentava com seu supervisor Sr. Arquimedes, que tal qual seu homônimo italiano, era muito metódico e por isto sempre questionava José sobre a fonte daquele seu apontamento e utilidade. Para José, os apontamentos do Sr. Arquimedes serviam como um teste que verificavam o quanto ele compreendia sobre o que falava. Costumeiramente, ao final das indagações, Sr. Arquimedes comentava com José: - 'Interessante!
Vivendo e aprendendo! Pode deixar que vou repassar para o pessoal responsável'. Depois, complementava: - 'Meu Filho, não se preocupe, também cobrarei a execução!'. José ria junto e dizia que, para ele, desafios sempre eram bem-vindos.

O contrato do estágio de José possuía um prazo limite e, ao final do período, José foi convidado a ir ao departamento de talentos da empresa, que antigamente era denominado recursos humanos. Lá José recebeu o feedback do seu período de estágio na empresa, com muitos elogios avalizados pelo Sr. Arquimedes, que sempre comentava das contribuições do jovem estagiário, além de ser informado que a empresa teria interesse em efetivá-lo, no entanto, isto deveria ocorrer em uma nova unidade que estava em fase de inauguração no estado do Paraná. Ao ver a expressão de preocupação na face de José, Sr. Antonio (gestor de talentos da empresa) explicou: 'José, grandes profissionais sempre terão que tomar grandes decisões. Então, não se preocupe, eu vou te repassar a proposta em um documento e você terá 3 dias para pensar e conversar com a sua família'. Neste momento José agradeceu a atenção do Sr. Antonio e foi para casa pensando no que fazer, como fazer e quando fazer.

\section{Rebobinando o motor}

Naquele mesmo dia José foi procurar o seu pai na oficina. Chegando lá encontrou ele rebobinando um motor elétrico. Após contar tudo o que o Sr. Antonio havia lhe falado, ouviu do Sr. Adão: - 'Bem meu filho, primeiramente, parabéns! Este tipo de oferta não é todo dia que ouvimos. Quanto a decisão a tomar, você sabe o que eu estou fazendo agora?' José logo respondeu: - 'Claro! Está rebobinando este motor!'. Então, Sr. Adão complementou: - 'Pois é, nossa vida é muito parecida com isto. Existem momentos em que teremos que retificar nossas vidas, ou seja, rebobinar, em outros momentos, não será necessário tanto, apenas precisamos lubrificar as partes. Normalmente, quando motor é novo, até pode parecer que precisa de grandes consertos, mas na verdade não precisa de muita coisa, apenas pequenos ajustes, pois uma retífica neste momento pode ser apenas um desinvestimento. Espero que minha parábola te ajude na tua decisão, de qualquer forma, lembra quando eu te falei que a empresa estava de portas abertas para quando quisesse retornar? Pois bem, continua e sempre continuará'.

No dia seguinte, José agradeceu a proposta de Sr. Antonio, no entanto, informou que não iria aceitar a 
oferta da empresa. Mais tarde, retornou a empresa do pai para ser recontratado. Todavia, para sua surpresa, Sr. Adão estava contratando-o neste momento para ser técnico da empresa. De acordo com Sr. Adão, José agora iria assumir a função do técnico mais antigo da empresa, que se aposentara. Nesta nova função, José teria que coordenar uma equipe agora composta por 14 profissionais. A cada dia encontrava-se mais determinado a colocar em prática tudo o que havia aprendido no curso técnico e nos anos de experiência, seja na própria empresa, ou na que fora estagiário.

Após cerca de um ano, começou a participar também das atividades administrativas, auxiliando o seu pai na gestão da empresa. Assim, José passou a ter contato direto com fornecedores e criou um relacionamento positivo com os representantes das empresas que lhe forneciam peças, além de aprender com o Sr. Adão algumas técnicas para administrar o negócio. Após algum tempo, José estava casado com Mariana, com quem possuía um filho e, então, sentia que precisava contribuir mais com o negócio e aumentar o seu faturamento. Assim, percebeu que precisava atualizar a empresa, utilizando novas técnicas de gestão e de produção. Desta forma, começou a realizar alguns cursos de atualização gerencial junto a empresas especializadas, procurando identificar melhorias para o empreendimento da família.

\section{O curto circuito}

Se, por um lado, José buscava novas técnicas gerenciais, por outro, Sr. Adão não queria modificar a empresa que ele erguera no passado. Assim, as iniciativas de José constantemente eram contestadas e reprovadas pelo Sr. Adão, que invariavelmente dizia: - 'José, é melhor não mexer em time que está ganhando há anos, inclusive antes mesmo de você nascer, então não iremos modificar nada'. Nestes momentos, o conflito, inerente às empresas familiares era iniciado. $\mathrm{Na}$ sequência, José respondia: - 'Pai, realmente, funcionou até agora, mas teremos que nos adequar aos novos tempos. Não podemos ser relógios analógicos em tempo de digitais'.

Por muitas vezes D. Adélia e Mariana tinham que intermediar a relação de pai e filho. D. Adélia, costumeiramente dizia: - 'Adão, você tem que entender que o tempo está passando e o que era certo antes, talvez não seja o melhor para hoje’. E complementava: - 'O José estudou e continua a estudar, será que não é o momento de deixar ele tomar as decisões?!'. Por outro lado Mariana falava a José: - 'José você não pode esquecer que a empresa é a vida do teu pai, ele passou praticamente toda a vida dele lá e fazendo da forma como ele sempre achou ser o certo, e não podemos dizer que deu errado! Ou podemos?!'. Nestes momentos, mesmo em casas diferentes, pai e filho ficavam a pensar sobre tudo e analisavam as situações mais calmamente.

Embora os dois acabassem sempre se acertando, José sabia que aquela situação não poderia continuar desta maneira. Por outro lado, já não era mais adolescente e teria que pensar na manutenção da sua família também. Então, chegou à conclusão de que precisava procurar uma alternativa, que não poderia seguir trabalhando com o seu pai naqueles moldes por muito tempo.

\section{0 cavalo encilhado - será?!}

Certo dia, um dos representantes que visitava a loja do Sr. Adão e José com uma frequência mensal, chamado Fernando, apareceu na empresa e falou que estava recrutando uma assistência técnica na cidade para que se especializasse somente na sua marca de equipamentos do segmento de ferramentas elétricas. A empresa, da qual Fernando era representante, conserva o renome mundial há anos e sempre foi reconhecida por possuir os produtos com a maior qualidade na sua área de atuação. Então, entre um café e outro, Fernando fez a oferta ao Sr. Adão: - 'Sr. Adão, trabalhamos juntos há muitos anos e, por isto, lhe conheço bem como profissional e pessoa que é. Então, nada mais justo, que oferecer para o senhor esta oportunidade. $\mathrm{O}$ que acha meu amigo, vamos fechar mais este negócio?'. Na sala encontravase, também, José, que ficou apenas obervando o diálogo dos dois. Então Sr. Adão exclamou: - 'Olha Fernando, fico feliz com a impressão sobre mim, pode ter certeza que a recíproca é verdadeira. Mas me fale, quais são as condições para eu aceitar esta proposta?'. Neste momento Fernando explicou: - 'Olha Sr. Adão, o Sr. terá que pensar nas oportunidades, que são enormes, pois o Sr. sabe que a minha marca é conhecida em qualquer lugar do mundo, mas, respondendo a sua pergunta, o Sr. não poderá trabalhar com outras marcas além da minha, no entanto, nós lhe daremos toda assistência, treinamento e suporte diferenciado. Esta ajuda e parceria que terá conosco, hoje o Sr. não tem”.

Fernando, percebendo o semblante de preocupação do Sr. Adão e José, continuou: - 'Sr. Adão, em respeito a nossa história de negociações e por pensar que o senhor e o José são as pessoas certas para a minha proposta neste momento, vou deixá-los pensar até amanhã a tarde'. Neste momento, Fernando se 
despediu e deixou pai e filho pensando sobre o cenário que acabara de se desenhar. Sr. Adão trabalhava com várias marcas e não pensava deixar de consertar as outras máquinas para se especializar somente em uma categoria. No entender dele, isto modificaria completamente a estratégia da empresa e reduziria o seu público-alvo, o que poderia levá-lo à falência. $\mathrm{Ou}$ seja, para o Sr. Adão, a gestão deveria estar focada na melhoria do que já fazia e, com isto, o processo de inovação poderia ser um risco para a gestão.

Por outro lado, esta poderia ser a oportunidade de José iniciar o seu próprio empreendimento e aplicar nele todo o conhecimento adquirido com o seu pai, com o estágio, com as suas experiências e com os cursos realizados. Para José, parecia ser o cavalo encilhado da sua vida. Naquele dia não se sentiu confortável em conversar a respeito de seu desejo com o pai. A noite, já em casa, conversou com Mariana sobre a proposta e seu desejo. Mariana o escutou atentamente e falou: - 'Bem José, eu não entendo muito de negócios, mas se você acha que é uma boa oportunidade, conte comigo, te ajudo em tudo o que você precisar. Só tem uma coisa'. Neste momento José olhou-a fixamente enquanto ela concluía: - 'A principal pessoa que você terá que conversar e se entender não é comigo e nem com a D. Adélia. Então, você já sabe com quem terá que falar'. Neste momento José balançou a cabeça como quem concorda plenamente com tudo o que foi dito.

Naquela noite, José não dormiu. Suas companhias durante a madrugada foram a angústia e o computador. Neste último, realizou diversas pesquisas sobre a empresa que almejava ser representante. Pesquisou sobre os produtos, sobre a empresa, traçou de que forma poderia trabalhar, o que poderia adicionar como assistência técnica (criar/inovar), o que poderia ajustar (melhorar) em função das experiências que já obtivera na empresa do seu pai e na que foi estagiário. Ao mesmo tempo em que fazia seus planos em uma folha de papel, a insegurança e o medo de empreender em algo novo assolavam seus pensamentos.

No outro dia, antes que o Pai saísse para trabalhar, resolveu conversar com ele. Assim, enquanto Sr. Adão tomava seu café da manhã, deparou-se com a imagem de José e de imediato o questiona: - 'José, meu filho, tudo bem contigo?', obtendo uma resposta rápida: 'Tudo, tudo Pai! Não se preocupe. Estou aqui porque precisamos conversar sobre os negócios'. Logo entra na cozinha D. Adélia, que beija a testa de José e fica a escutar a conversa entre o patriarca e seu primogênito.
Assim, José começou explicando que ficara pensando sobre a proposta de Fernando, mas sua intenção não era a de modificar a empresa do Sr. Adão, que, como ele sempre comentou, 'o time estava ganhando', mas sim abrir a sua própria assistência destinada a representar a multinacional em que o Fernando era funcionário. E complementou: - 'Pai, sinto que este é o meu cavalo encilhado que está passando! E se não montar agora, poderá ser tarde amanhã!'. Neste momento Sr. Adão, parou por alguns segundos saboreando uma xícara de café, e perguntou: - 'José e a nossa empresa? Eu sei que não abro muito espaço para você agir, mas no fundo o negócio é seu! Eu e a tua mãe trabalhamos a vida inteira para construir algo para deixar para você! Quem sabe nos ajustamos à proposta do Fernando e você continua na empresa!? Será que este é realmente o teu cavalo encilhado?'. Então José complementou: - 'Pai, o Sr. sempre me ensinou que deveria trabalhar e estudar que tudo daria certo na vida, então, estou trabalhando e estudei, acho que chegou a minha hora! Já pensei em como trabalhar, onde trabalhar e o que fazer, embora precise de sua ajuda para não errar nos meus planos. Ainda assim, se der tudo errado, terei a sua empresa para retornar. Já fiz isto uma vez, poderei fazer uma segunda vez, ou não?'. Neste momento, D. Adélia, sem falar nada, bate no ombro direito do Sr. Adão, olhando fixamente para Sr. Adão e, após um instante de olhares, Sr. Adão expressa: - 'Meu Filho! Sempre estaremos contigo! Sei o quanto te dedicou, estudou e, no passado, também tive que tomar as minhas decisões, e não me arrependo'. E, finalizando, expressou: - 'Então, monta neste cavalo e o faz galopar e, em tudo o que precisar, conte com estes dois velhos!'.

Neste instante D. Adélia pega o bule de café e serve as xícaras de seu marido e filho e complementa: - 'É uma honra servir uma dupla de empresários! Se precisarem de alguém para fazer café, me digam para onde mando meu currículo'. Na sequência os três começam a rir e comemorar.

\section{Negócio fechado, ou melhor, negócio aberto}

No final da tarde, conforme combinado, Fernando retornou até a empresa de Sr. Adão para verificar se ele já havia pensado sobre o assunto. Ao chegar ao local, Fernando logo exclama ao Sr. Adão: - 'Boa tarde meu amigo! Vim aqui para fecharmos negócio, ou melhor, para abrirmos negócios!'. De pronto Sr. Adão completa: - 'Então considere o negócio aberto!'. Neste momento Fernando expressa um 
sorriso de felicidade no rosto e retorna: - 'Eu sabia que o Sr. iria aceitar a minha proposta, certamente não se arrependerá!'. Em seguida o Sr. Adão completa a fala: - 'Olha Fernando, continua tudo em família, mas quem irá aceitar a proposta é ele’ e faz um gesto apontando para José. Depois complementou: 'Acredite, sei que sou suspeito para falar, mas ele é ótimo em tudo o que faz, sei que dará conta desse desafio também!'. Neste instante, Fernando olha para José e direcionando-se a ele estende a mão e fala: 'José, te conheço tanto quanto conheço o teu pai e sei que estou fazendo um ótimo negócio, então posso considerar o negócio aberto?!'. Ao que José estende a mão cumprimentando-o e expressa: - 'Você não irá se arrepender, faremos uma excelente parceria! Negócio aberto!'.

O negócio foi aberto 2 meses após a visita de Fernando à loja do Sr. Adão. José iniciou suas atividades na garagem da sua casa, na qual trabalhavam ele, Mariana e um funcionário, que fazia o serviço técnico de conserto das máquinas. No primeiro dia de atividades, Sr. Adão juntamente com D. Adélia apareceram na loja do filho com várias caixas, ao que foi questionado por José com um sorriso no rosto: - 'O que é isto pai, está de mudança para cá?’. E foi complementado pelo Sr. Adão: - 'Ainda não meu filho! Toda a casa nova tem que ter um enxoval e estamos lhe dando o seu. Nestas caixas estão todas as peças da marca que você é autorizado e que eu possuía no estoque da minha loja., Agora são suas!'. E também queroavisar que já comuniquei a fábrica que a partir de hoje não trabalho mais com esta marca!'. Sr. Adão olhando nos olhos do filho, cheio de lágrimas, continuou: - 'A nossa concorrência será apenas pela atenção da tua mãe!'. E na sequência ambos se abraçaram por um longo período de tempo.

O endereço do empreendimento permaneceu durante um ano. Após este período, José e Mariana conseguiram adquirir um imóvel comercial e se mudaram para o centro da cidade, possuindo boa localização e, assim, estando na vitrine para os clientes em potencial. Isso era fundamental na época, pois José não possuía recursos para investir em publicidade e precisava que os novos clientes conhecessem a sua empresa e a forma diferenciada com que trabalhava.

\section{Inovar e/ou melhorar - Eis a questão!}

Com o novo endereço, José alcançou maior visibilidade para o seu empreendimento, como havia planejado. Ele e sua esposa Mariana continuaram trabalhando juntos com apenas um funcionário nos dois anos seguintes. Então, certo dia no almoço, Mariana contou sem rodeios: - 'José, estou grávida!' José, gaguejando de emoção exclamou: - 'Meu Deus! Que notícia maravilhosa!' Na sequência, abraçou Mariana e beijou a sua barriga. À noite, antes de dormir, José ficou pensativo: - 'Estou muito feliz por estar à espera do meu segundo filho, mas agora Mariana não vai poder me ajudar tanto na empresa e terei que contratar outro funcionário, logo, terei mais despesas que não sei se conseguirei dar conta'. Naquela noite, José foi dormir com um misto de felicidade e nervosismo.

Após alguns meses procurando um funcionário que o ajudasse na área técnica e também auxiliasse no atendimento aos clientes, pois, segundo o seu pai, em pequenas empresas 'todo o jogador deve saber passar a bola, cruzar e chutar a gol', José contratou um rapaz recém-formado no mesmo curso técnico que ele e este fato já era por si só uma excelente referência, pois conhecia o rigor do curso.

Mesmo com os dois funcionários, José possuía angústias que o consumiam. Após o nascimento da sua herdeira, os sentimentos de realização ao contemplar a sua família eram poluídos por inquietações a respeito da condução dos negócios e resultados da empresa. Afinal, como José sempre dizia aos seus funcionários: - "Não posso errar, pois tenho mais uma pessoa para sustentar".

A cabeça de José só estava focada no seu negócio e ele se pegava pensando em diversos momentos: - 'Como eu posso crescer? Como eu conseguirei aumentar o meu faturamento? A empresa é a única fonte de renda da minha família, preciso urgente de um plano estratégico bem elaborado para conseguir gerar mais lucro e poder sustentar dignamente minha mulher e meus filhos. Não quero que eles passem necessidade ou lhes falte algo, ao contrário, quero que tenham uma vida boa e eu vou dar isso a eles!'. Ele então percebeu que estava com medo de não saber investir corretamente os seus escassos recursos, ou seja, se preocupava em fazer movimentos que acabassem por consumir demais e não tivessem retornos financeiros, e isto poderia se refletir em erros não somente na empresa, mas principalmente, na sua família.

José resolveu então conversar com o seu pai sobre o seu medo e pedir algumas dicas. Sr Adão logo falou: - 'Isso que você está passando é normal, José. Eu mesmo já senti este medo várias vezes, e não pense que foi somente no começo, até hoje ainda sinto. 
Em algumas situações é melhor arriscar, lógico que de maneira consciente e, em outras, vale mais a pena continuar do mesmo jeito e não colocar tudo a perder, fazendo apenas pequenos ajustes, pois ficar parado é muitas vezes pior do que se movimentar devagar. $\mathrm{O}$ mais importante é avaliar todas as alternativas e ter certeza de que é o melhor a fazer. Se você acha que consegue diminuir um pouco os gastos pessoais para investir no crescimento da empresa, faça isso!'.

José foi para casa conversar com a Mariana, contou o que o seu pai the falou e perguntou o que ela achava, logo ela respondeu: - 'José, nós temos um bebê e uma criança, agora estamos gastando bem mais do que antes. Mas eu acredito que podemos segurar as pontas um pouco, para você ir guardando dinheiro para ser aplicado na empresa'. Então José fez uma planilha com os seus gastos e planejou o que poderia gastar nos próximos meses e como economizaria o seu dinheiro. Assim, percebeu que teria que trabalhar algum tempo com os dois funcionários apenas e que não poderia investir em outras coisas além das compras e despesas do empreendimento, mas que em breve poderia fazer maiores investimentos.

Após alguns dias, José estava reorganizando o seu escritório em casa quando observou que sua filha pequena (Aline), estava mexendo nos antigos livros que os professores Gean e Afonso haviam lhe dado. Logo pensou: - 'Mas eu tenho sorte mesmo! Eu já havia esquecido esses livros e eles reapareceram logo agora, em um momento tão oportuno! E olha quem acabou por me mostrá-los'. Nos dias seguintes, então, se dedicou a reler os livros sobre ambidestria e anotar todas as informações que poderiam ser relevantes no seu caso. O que chamou a atenção de José é que todas as suas leituras reforçavam a relação positiva entre as ações dos gestores em criar (explorar) novos produtos e serviços, ao mesmo tempo em que melhoravam (explotar) os que já haviam criados e o desempenho das empresas. E desempenho era o que ele buscava. Mas, mesmo com leituras e pesquisas, uma dúvida era recorrente na mente de José: - 'Como eu vou investir em uma estrutura dual (explorar/explotar) na empresa se não tenho muitos recursos?

$\mathrm{Na}$ mesma hora teve a ideia de falar diretamente com quem entende do assunto e marcou de tomar um café com o Prof. Afonso, que encontrava prestes a se aposentar, mas que ainda gostava muito de pesquisar e se mantinha sempre atualizado nos temas de sua área. Em um primeiro momento, conversaram sobre assuntos diversos, sobre as notícias atuais do Brasil e do mundo e sobre as suas vidas desde que José se formou no curso de eletrotécnica. Em seguida, José contou do seu negócio e sobre como ele funcionava, ao que Afonso exclamou: - 'Que legal José! Eu sempre soube que, além de ser um ótimo aluno, você seria um excelente profissional! Fico feliz de ver que você investiu em algo novo e diferente do tradicional, ou seja, as minhas aulas sobre inovação tiveram essa utilidade'. Os dois riram e, em seguida, José respondeu: - 'Sim, graças ao senhor e aos outros professores, tive uma ótima formação, muito obrigado!'. - 'Não precisa agradecer José, você não sabem o quão satisfatório é saber que nós fizemos a diferença na vida profissional de alguém, instruindo a se tornarem pessoas capacitadas para o mercado de trabalho'.

José, mais tarde, entrou no assunto sobre o qual ele buscava respostas: - 'Professor, o Sr. lembra que a gente havia conversado sobre ambidestria e o Sr. me emprestou um livro sobre esse tema na época em que eu estava tendo aula com o Sr?'. O Prof. Afonso respondeu: - 'Claro que lembro, você estava bastante interessado na época. O material serviu para responder as suas questões?'. José no mesmo momento declarou: - 'Serviu sim, aproveitei ao máximo ele na época e, não vou mentir, após isso, deixei ele guardado numa gaveta por um bom tempo. Aí essa semana estava mexendo nas minhas coisas do escritório e encontrei-o. Reli tudo, estudei sobre o tema, mas acabei ficando com algumas dúvidas: eu gostaria de implantar a ambidestria no meu negócio, pois quero aumentar o meu faturamento, no entanto, não possuo recursos para inovar e para aprimorar os meus serviços ao mesmo tempo. Estes tipos de estruturas duais existem mesmo? É possível fazer os dois movimentos, de exploração e de explotação, ao mesmo tempo?'.

O Prof. Afonso explicou: - 'Nas teorias seminais, há muitos anos, se defendia que sim, que era possível e, também, recomendado colocar em prática os dois tipos de inovação ao mesmo tempo. No entanto, em seguida, várias pesquisas empíricas mostraram que podem ser feitos muitos arranjos, sendo possível, por exemplo, a empresa utilizar $10 \%$ da sua estratégia ambidestra focada na exploração e os outros $90 \%$ na explotação. Os estudos verificaram, também, que a utilização dos dois movimentos concomitantemente é aconselhável e praticável quase que exclusivamente pelas grandes empresas, pois, na média, elas possuem mais recursos e têm a possibilidade de se estruturar de forma a praticar este tipo de ambidestria'. E 
acrescentou: - 'Portanto, não se preocupe José, você pode focar em um tipo de inovação mais do que em outro, sem problemas. Agora resta somente você decidir se será mais destro ou canhoto, pois se você utilizar as duas mãos já é considerado ambidestro!

Naquela noite, José não conseguiu dormir. Ficou acordado com os seus pensamentos e, olhando para suas mãos, se perguntava: - 'É mais interessante investir em algo novo para a empresa agora? Ou eu teria um retorno mais rápido se eu aprimorasse os serviços que já ofereço e aumentasse o meu estoque de produtos ofertados?'

José verificou também que o mercado estava se atualizando e utilizando novas tecnologias em todos os setores, mas seria necessário investir naquele momento nesse tipo de modificações? Ele teria algum retorno sobre isso? Afinal, José não tinha nenhum concorrente direto na região, então não tinha a preocupação em se modernizar o mais rápido possível, pensava que era melhor executar bem o seu serviço e dar um bom atendimento aos clientes, a fim de fidelizá-los, como seu pai sempre fez.

No entanto, como previsto por José, a marca com a qual ele trabalha passou por uma reestruturação, passando a utilizar softwares modernos e quase todas as suas operações se tornaram online. José, então, foi pressionado pelos representantes da marca a se atualizar, mas se deparou com outro dilema: o quanto ele deveria investir nessas novas tecnologias? Se investisse muito, ele poderia não conseguir se adaptar ou elas poderiam se tornar obsoletas depois de um tempo e ele veria o seu dinheiro sendo mal empregado, tendo depois que reinvestir muito, novamente, em outra tecnologia. Se investisse pouco, poderia não ser suficiente para as suas necessidades - que estavam se modificando - e ele teria perdido tempo e dinheiro com algo que não supre as suas carências.

Além disso, outra questão com a qual José se deparou foi com os novos entrantes no mercado. Com o tempo foram surgindo várias marcas que competiam principalmente por preço e José foi percebendo que, mesmo não possuindo concorrente direto no seu negócio, ele tinha muitos concorrentes indiretos. A marca com a qual José trabalhava também percebeu este problema e passou a lançar novos produtos a todo o momento e a diversificar a sua linha, o que tornou mais difícil a atualização dos funcionários sobre os produtos e requeria um maior número de treinamentos e atualizações.
José sentia, e sente até este momento, a necessidade de expandir as suas vendas e aumentar o seu faturamento, para poder continuar investindo e crescendo, mas não sabia como fazer isso, pois estava amarrado a uma só marca e não poderia diversificar a sua linha de produtos e serviços, o que restringe as suas alternativas. Assim, algumas dúvidas povoavam sua mente em tempo integral, sendo contrastadas sempre com uma única contraposição: recursos como pagar? Tais inquietações podem ser observadas na figura 1.

Figura 1. Dúvidas/inquietações de José

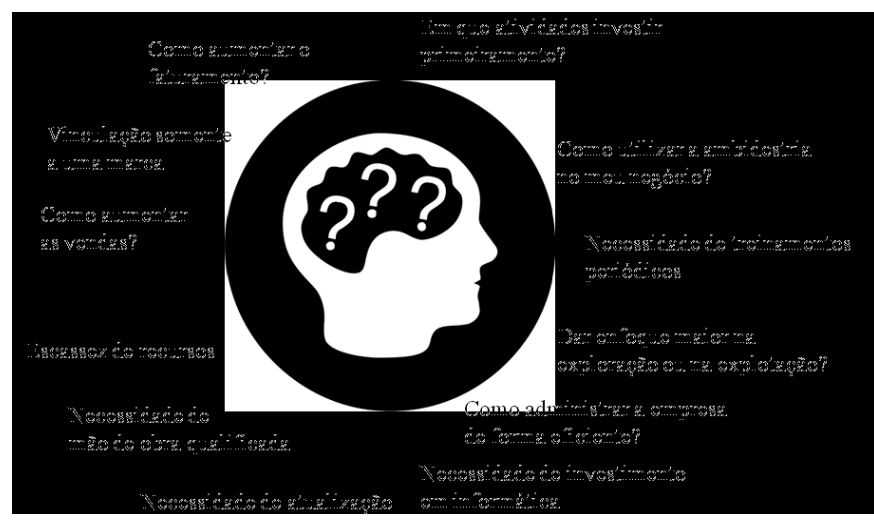

Fonte: Elaborado pelos autores

\section{E agora José?}

A primeira coisa que José decidiu foi a sua própria atualização sobre o mercado, deixando para um segundo momento resolver o problema de onde investir na empresa. Assim, buscou fazer alguns cursos sobre gestão e contratou um serviço de consultoria para o seu negócio. A partir daí, ele conseguiu refletir melhor sobre quais decisões deveria tomar dali em diante.

O serviço de consultoria primeiramente o auxiliou a reestruturar o layout da empresa para atender melhor os clientes, portanto, modificaram os balcões de atendimento e a fachada da empresa, organizaram os locais de cada produto e colocaram a bancada onde se efetuam os consertos próxima dos balcões, deixando-a mais visível, a fim de que os clientes tenham a possibilidade de acompanhar o serviço que está sendo realizado na sua ferramenta, o que passa maior credibilidade e aumenta a confiança do cliente na empresa. 
Depois, o consultor questionou sobre a questão financeira da empresa: - 'Como o senhor mantém o seu planejamento financeiro? E qual a área da empresa que o senhor acredita ser a que necessite de maior investimento?' José respondeu que gostaria de investir mais em tudo, mas o que faltava era dinheiro. O consultor então exclamou: - 'Não se preocupe, pois esse é um problema comum a todos! O mais importante é se organizar e focar no que considera ser primordial, deixando o que é secundário para depois. Então vamos nos organizar e trabalhar!'. José decidiu então investir na tecnologia necessária para o seu negócio - nada muito moderno, evitando altas despesas -, em treinamentos mensais para os seus funcionários e na melhoria contínua dos seus processos. Mas ele ainda queria mais, ele almejava aumentar, e muito, o seu volume de vendas, seu número de clientes e seu faturamento.

Fernando, que continuava sendo representante da marca e que fazia visitas mensais a José, costumava sair para jantar com ele, o que rendia muitos assuntos informais e alguns assuntos profissionais, estreitando os laços deles. Em um destes jantares, José estava comentando sobre querer crescer mais, mas sentir dificuldade pelo fato de estar atrelado a uma só marca e não poder expandir a sua oferta de produtos e serviços. Ele então lhe disse: - 'Eu tenho percebido uma coisa no nosso mercado: por termos poucos negócios como o teu, especializado na nossa marca, e por ser difícil comprar diretamente da nossa fábrica, como você o faz (por conta do alto volume mínimo solicitado pela mesma), eu vejo que muitas oficinas menores, que trabalham com muitas máquinas, não conseguem comprar as peças da nossa marca e, portanto, acabam não consertando as nossas ferramentas, mesmo possuindo interesse. Você não acha que seria uma boa ideia investir nessa revenda de peças para empresas que consertem ou que tenham interesse em consertar as nossas máquinas? Isso aumentaria o volume de itens que você iria comercializar e, consequentemente, aumentaria o seu faturamento'. José, de imediato, exclamou: - 'Sempre com ótimas ideias Fernando! Além de trazer o meu cavalo encilhado, agora está me ajudando a domá-lo!'. Os dois riram juntos e apertaram as mãos.

José necessitou contratar outro funcionário para esta inovação, dessa vez escolheu uma mulher, a Joana, para fazer as atividades ligadas a essa área, que requeria muita atenção e tempo dedicado, pois era preciso fazer a prospecção dos clientes, contatá-los, passar informações técnicas, comunicá-los sobre os valores e condições de pagamento e todo o processo de venda, o que é muito mais complexo que a venda direta a clientes pessoalmente. Inicialmente, José passava para Joana apenas o principal e repetia constantemente: 'Vende o teu peixe! Mostra para eles que nós, além de possuirmos o preço mais baixo de todo o estado, ainda oferecemos um atendimento de qualidade e daremos suporte técnico sempre que necessário'. Após poucos meses, a empresa de José já tinha uma ampla carteira de clientes fiéis nessa nova área de revendas.

O negócio que José montou levou mais de quinze anos para chegar ao nível que ele almejava no início e estava finalmente rendendo bons frutos. No entanto, todos sabem que não se pode parar de se atualizar e de almejar voos mais altos. Assim, há cerca de 5 anos o planejamento estratégico da empresa foi totalmente reestruturado. A empresa inovou radicalmente de novo, se tornando um 'centro técnico', especializado na mesma marca e oferecendo todas as soluções aos clientes com relação às ferramentas que comercializa. Esta inovação se tornou um diferencial para o negócio de José frente à concorrência indireta, pois na região não existe nada semelhante com a proposta e, além disso, fez com que a empresa não perdesse o foco. Mantendo essa estratégia, no final de 2016, a empresa ficou no ranking como a segunda maior compradora da marca dentro do estado. Atualmente a empresa continua com seus indicadores alinhados com os projetados em seu planejamento, além da manutenção nos rankings do segmento.

No entanto, alguns questionamentos ainda pairam no ar: como José pode investir em algo totalmente novo se ele está limitado ao que é produzido pela marca? Existem alternativas de inovações que podem ser utilizadas por José? Quais outros recursos ele pode utilizar para aumentar o seu leque de clientes e o seu faturamento? Neste caso, a utilização de estratégias organizacionais ambidestras é válida? Balanceadas entre exploração e explotação, ou não?

\section{Notas de ensino - diretrizes para professores}

\section{Objetivos educacionais}

Tomando como base o perfil dos personagens do presente caso para ensino, em contraste com suas trajetórias empresariais, tomadas de decisões 
e resultados, apresenta-se a seguir os objetivos educacionais propostos para o pleno desenvolvimento das atividades:

- Contextualizar a realidade empresarial de um setor específico com suas particularidades (generalista/ especialista);

- Demonstrar diferenças entre os perfis de tomadores de decisões;

- Apresentar o conceito de ambidestria organizacional a partir da realidade empresarial;

- Discutir as tomadas de decisões de exploração e/ou explotação de produtos ou serviços em um contexto de pequena empresa;

- Refletir sobre a necessidade de um balanceamento entre as ações de criação e melhoria.

\section{Informações sobre os personagens}

Os personagens e suas trajetórias empresariais representam a realidade vivenciada. No entanto, os nomes dos participantes foram alterados, preservando suas identidades, conforme solicitado durante a coleta de dados. A empresa em estudo apresenta continuamente aumento no volume de comercialização de seus produtos e destaca-se entre as assistências técnicas no cenário da marca que comercializa seus produtos no âmbito mundial.

\section{Utilização recomendada}

Sugere-se que o presente caso para ensino seja utilizado em disciplinas que abordem tomadas de decisões de gestores em ambos os níveis organizacionais: macro e micro ambiente. Ademais, acredita-se que a temática possua maior aderência com as disciplinas que versem sobre estratégia, planejamento estratégico, empreendedorismo, marketing, tópicos contemporâneos em administração, entre outras.

Ademais, o caso poderá ser utilizado em cursos de níveis de graduação, especialização, mestrado ou doutorado, além de cursos de extensão ou curta duração, desde que reconhecida a importância de conhecimentos basilares sobre organizações e gestão. Sob outra ótica, orienta-se a utilização deste caso para ensino, também, em universidades empresariais, como fonte de discussão sobre cenários e estratégias organizacionais.

\section{Situação-problema}

O caso para ensino apresentado aborda a temática de formulação de estratégias a partir do contexto de um representante autorizado de uma marca reconhecida internacionalmente. Em um primeiro momento, por conta da consolidação da marca, poder-se-á imaginar que as estratégias a serem desenvolvidas não possuam complexidade, no entanto, o gestor depara-se com uma sequência de angústias gerenciais que o motivam a projetar cenários e, com base neles, projetar os rumos da organização. Neste sentido, este caso tem o objetivo de balizar os discentes para que interpretem o cenário organizacional micro e macro, posicionando-se em relação as tomadas de decisões centradas em dois movimentos principais: i) criar ou melhorar os processos/produtos; ou; ii) criar e melhor os processos/produtos, amparados no contexto empresarial apresentado no texto.

\section{Sugestões de questões para discussão}

1. Quais os pontos positivos e negativos de se especializar e de estar vinculado exclusivamente a uma única marca, como no caso de José?

2. Qual a atividade da empresa que precisa receber maior atenção e investimento financeiro?

3. Discuta se, no cenário atual do mercado brasileiro, a decisão de José de se especializar em somente uma marca poderia ser utilizada como uma estratégia de exploração.

4. Em quais pontos, com base na teoria de March (1991), José inovou de modo exploratório? E explotatório?

5. Quais as alternativas que José possui se quiser investir, ainda mais, em uma inovação exploratória? E se quiser continuar inovando explotativamente?

6. José é um empreendedor com características ambidestras? Explique com exemplos do caso.

7. Como José poderia criar (explorar) no seu negócio sendo representante de uma marca?

8. Como José poderia melhorar (explotar) o seu negócio sendo representante de uma marca?

9. Com quais teorias a estratégia ambidestra pode ser relacionada? 
10. De acordo com a teoria da qual o nível (quantidade) ideal de ações de exploração e explotação necessários para ser considerada uma estratégia ambidestra? Neste sentido, senão existir a mesma quantidade poderá ser considerada como tal?

11. Você concorda que a ambidestria é aderente a uma corrente teórica de inovação organizacional? Justifique.

\section{Análise do caso}

\section{Ambidestria Organizacional}

A ambidestria organizacional possui suas raízes conceituais no estudo de Duncan (1974). De acordo com o cientista, a ambidestria deveria ser analisada como um modelo para organizações, cujas estratégias estariam direcionadas a inovação. Desta forma, a mesma deveria estar alicerçada em dois movimentos: inovação e implementação. Mais tarde, March (1991), reapresentou o modelo de ambidestria, com contribuições à teoria inicial. Assim, a ambidestria passou a ser concebida pelos movimentos de exploração - anteriormente, para Duncan era definido como inovação - e explotação - para Duncan era a implementação -, entendidos como movimentos concomitantes e complementares. Embora, Duncan (1974) tenha sido o precursor dos estudos sobre ambidestria, Silveira-Martins e Rossetto (2014) destacam que o trabalho de March (1991) foi o mais referenciado em um levantamento bibliométrico realizado, compreendendo um espaço temporal de 17 anos em referências internacionais.

Assim, de acordo com March (1991), as atividades de exploração estão relacionadas com: 1) variação; 2) busca; 3) tomadas de decisões com riscos; 4) experimentação; 5) flexibilidade; 6) descoberta; e; 7) inovação de produtos e/ou serviços. Em outra extremidade a explotação relaciona-se com: 1) refinamento; 2) escolha; 3) produção; 4) eficiência; 5) seleção; 6) implementação; 7) execução das atividadesfim da organização. De maneira análoga, pode-se conceber que o gestor ambidestro é semelhante a um malabarista, que precisa fazer movimentos sincrônicos e constantes. Ademais, este malabarista organizacional, além de realizar movimentos ambidestros, terá que equilibrar-se sob os escassos recursos organizacionais. Logo, este tipo de estratégia exige um tomador de decisões apto a ser um malabarista/equilibrista com expertise em organizações e seus derivados. A Figura 2 exemplifica a analogia construída com base nos ensinamentos de March (1991).

Figura 2 . Analogia do gestor e as estratégias ambidestras

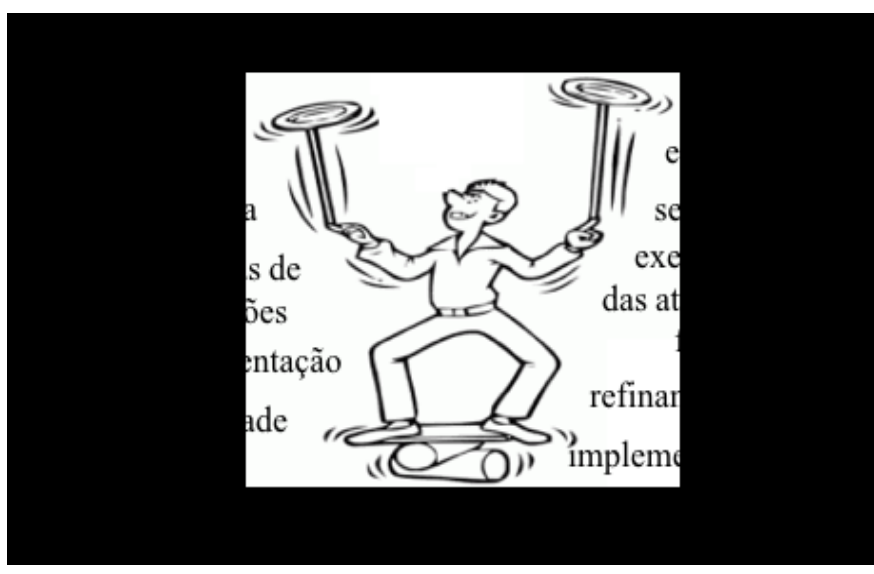

Fonte: Adaptado de March (1991)

Não obstante, verifica-se que a ambidestria organizacionalé reconhecida por muitos pesquisadores, como por exemplo, Tushman e O'Reilly (1996), como fonte de desempenho superior, quando compara-se as empresas duais com as que priorizam apenas uma das dimensões de inovação em detrimento da outra. Assim, este tipo de estratégia direciona a empresa a canalizar as suas vendas e ajustar os seus negócios em tempo de transição do mercado.

Este posicionamento é corroborado por Durisin e Todorova (2003), quando destacam que as organizações ambidestras tendem a inovar com sucesso tanto em casos de mudança evolutiva, quanto em casos de mudança revolucionária, através, fundamentalmente, da gestão múltipla e da utilização de padrões de arquiteturas organizacionais contraditórias. Este fato acaba tornando a implementação da estratégia ambidestra um desafio constante para as empresas.

Observa-se, portanto, que o pensamento de March (1991) e Durisin e Todorova (2003) é reforçado por He e Wong (2004). De acordo com estes pesquisadores a interação entre as estratégias de orientação exploratória e explotatória está positivamente relacionada com a taxa de crescimento das vendas nas empresas. Em contrapartida, o desequilíbrio entre as duas estratégias está negativamente relacionado com essa mesma taxa. 
Esta interpretação é contestada por Gupta, Smith e Shalley (2006), no momento em que os pesquisadores destacam que o desempenho organizacional poderá ser obtido com desenvolvimento de ações isoladas de exploração e explotação. Esta última visão citada, portanto, é contraditória aos ensinamentos de March (1991).

Para criar estruturas organizacionais ambidestras, os gestores devem desenvolver técnicas que permitam que as equipes sejam flexíveis, enquanto eles gerenciam o equilíbrio entre a necessidade de a organização ser centralizada e descentralizada, ser pequena e grande, ser focada no curto e no longo prazo, tudo isto ocorrendo simultaneamente (BENNER; TUSHMAN, 2003). Portanto, as unidades organizacionais devem se prevenir para não se tornarem obsoletas, pois o sucesso traz com ele a inércia organizacional (HE; WONG, 2004). Neste sentido, torna-se importante destacar os resultados encontrados por Purvee e Enkhtuvshin (2014). Segundo os autores, a liderança transformacional é positivamente influente na gestão ambidestra. Tal achado ganha maior evidência quando deparado com cenários que refletem ambientes dinâmicos.

Por outra ótica, Tinoco (2014) ressalta o fato de alguns acadêmicos argumentarem que as empresas têm a possibilidade de alcançar a ambidestria através de alianças e parcerias em vez de tomar para si, única e exclusivamente, tal responsabilidade. De acordo com o autor, este procedimento é verdadeiro, todavia, os gestores devem primeiro tomar a decisão estratégica de que a exploração e explotação serão simultaneamente desenvolvidas, conforme ensinado por March (1991). O emprego de vários processos dentro da empresa também ajuda nestas atividades, garantindo que o viés natural para uma ou outra dimensão seja reduzida. Com o emprego de estratégias ambidestras, as empresas podem desenvolver uma vantagem competitiva sustentável, que é difícil de imitar, valiosa, rara, e para a qual não há nenhum substituto, incorporando opostos processos de negócios (TINOCO, 2014).

Scott (2014) afirma que o gestor é o responsável pelo equilíbrio entre as práticas de exploração e explotação, o que, segundo o autor, é na teoria seminal é desconsiderado (papel do gestor). Ademais, para que a estratégia ambidestra seja consolidada como fonte de inovação, o gestor deverá integrar as seguintes estratégias: negócios, marketing e sistemas de informação. A estratégia de negócios deverá ressaltar a agressividade competitiva, defesa eficiente e análise do equilíbrio (exploração e explotação). A estratégia de marketing deverá enfatizar a consciência externa, consciência interna e congruência dos recursos para a inovação. Já a estratégia de sistemas de informação, deverá enfatizar a flexibilidade, eficiência e abrangência.

O papel do gestor na condução das estratégias ambidestras parece ser consenso entre a maioria dos pesquisadores, todavia, ainda existem lacunas no entendimento sobre as ações ambidestras propriamente ditas. Silveira-Martins et al. (2014) ao analisar o comportamento estratégico dos gestores, identificou que as orientações prospectora, analista e, curiosamente em função do preconizado pela teoria, também a reativa possuem relação com a ambidestria organizacional. Já a orientação estratégica caracterizada como defensora possui uma relação negativa com a ambidestria. Em complemento, Silveira-Martins e Rossetto (2014) afirmam que a manutenção das estratégias ambidestras deve ser conduzida considerando o ajuste constante das diversas variáveis que interferem no sistema organizacional (i.e. comportamento estratégico e ambiente, entre outras).

Seguindo o pensamento de Gupta, Smith e Shalley (2006), Ramachandran (2012) destaca que a ambidestria é reconhecidamente um mecanismo de gestão que a empresa poderá utilizar para administrar as ações de exploração e explotação. No entanto, o pensamento clássico de que o equilíbrio entre estas práticas é essencial para sobreviver e prosperar não pode ser entendido como uma verdade única. Assim, de acordo com o pesquisador, não há um padrão único de combinação de exploração e explotação para o desenvolvimento da ambidestria e, sim, combinações múltiplas, onde uma ação poderá ser coadjuvante da outra em determinado momento, sendo modificado este desenho em cenários divergentes. Desta maneira, o equilíbrio entre as ações é possível também, mas não é condição única.

Estimulados pelo debate entre os pesquisadores de diferentes correntes teóricas (que discutem o equilíbrio, ou não, entre as ações de exploração e explotação), Silveira-Martins, Rossetto e Añaña (2014) procuraram entender qual das atividades geram resultados, quando comparadas ao desempenho: ambidestria, exploração ou explotação. De acordo com os cientistas, tanto a ambidestria como a exploração ou explotação, quando analisadas isoladamente em relação ao desempenho possuem associação positiva. Logo, as estratégias poderiam ser direcionadas, amparadas na corrente seminal de March (1991), como também em ações isoladas de criação ou melhoria, conforme Gupta, Smith e Shalley (2006).

Como já argumentado por diversos autores, como Tinoco (2014) e Scott (2014), o gestor assume papel 
determinante na condução e sustentabilidade da ambidestria. Seguindo esta linha de raciocínio, Silveira-Martins e Vaz (2016) procuraram entender se a orientação empreendedora formada pela proatividade, inovatividade e assunção de riscos é fonte preditiva de ambidestria organizacional, obtendo resultado positivo. Ainda, de acordo com os autores, a ambidestria, por conta de suas características conceituais singulares, deve ser considerada também uma tipologia de capacidade dinâmica e, como tal, é associada positivamente com o desempenho organizacional.

Por outro prisma, a ambidestria organizacional pode ser influenciada, também, pelos fatores contextuais, tais como: treinamento, confiança, disciplina, pressão e apoio sobre os participantes da organização. Seguindo esta lógica, Ramos, Matos e Mota (2015) identificaram que tais fatores influenciam as capacidades inovadoras e, por conseguinte, a ambidestria organizacional - em especial de empresas de pequeno porte. A pesquisa também concluiu que a ausência dos fatores contextuais pode fazer com que não exista ações direcionadas à inovação.

As diferentes visões e posicionamentos conceituais dos pesquisadores parecem convergirem para o fato de que as ações de exploração e explotação, alicerces da ambidestria organizacional, seja de maneira concomitante ou não, equilibrada ou não, geram, conforme Karrer e Fleck (2015), tensões, trade-off, enigmas, dilemas e paradoxos nas organizações. Tal posicionamento pode ser observado no Quadro 1.

Quadro 2 . Múltiplas concepções sobre a relação entre exploração e explotação

\begin{tabular}{|c|c|c|}
\hline CONCEPÇÃO & EXEMPLOS DE PESQUISAS & TEXTO EXEMPLIFICATIVO \\
\hline Tensão & $\begin{array}{c}\text { Andriopoulos e Lewis (2009); } \\
\text { Chandrasekaran, Linderman e Schoreder } \\
\text { (2012); Chang, Hughes e Hotho } \\
\text { (2011); Judge e Blocker (2008); O’Reilly } \\
\text { e Tushman (2008, 2011); Raisch e } \\
\text { Birkinshaw (2008); Raisch, Birkinshaw, } \\
\text { Probst e Tushman (2009); Tiwana, (2008) }\end{array}$ & $\begin{array}{l}\text { Esta é a TENSÃO fundamental no coração } \\
\text { de uma empresa ao longo prazo objetivando a } \\
\text { sobrevivência. O problema básico que confronta } \\
\text { uma organização é o de se engajar em explotação o } \\
\text { suficiente para assegurar a sua viabilidade corrente } \\
\text { e, ao mesmo tempo, dedicar energia suficiente para } \\
\text { a exploração e assegurar a sua viabilidade futura } \\
\text { (O'REILLY; TUSHMAN, 2011, p. 1) }\end{array}$ \\
\hline Trade-off & $\begin{array}{c}\text { Ancona, Goodman, Lawrence e Tushman } \\
\text { (2001); Andersen e Nielsen, (2007); Cao, } \\
\text { Gedajlovic e Zhang (2009); Chang et al. } \\
\text { (2011); Floyd e Lane (2000); Gibson e } \\
\text { Birkinshaw (2004); He e Wong (2004); } \\
\text { Kyriakopoulos e Moorman (2004); } \\
\text { Levinthal e March (2003); Simsek, Heavey, } \\
\text { Veiga e Souder (2009) }\end{array}$ & $\begin{array}{l}\text { Exploração e explotação são fundamentalmente } \\
\text { diferentes lógicas que criam tensões. Elas } \\
\text { competem por recursos escassos das empresas, } \\
\text { resultando na necessidade de as empresas gerirem } \\
\text { os TRADE-OFFS entre as duas. (HE; WONG, } \\
\text { 2004, p. 481) }\end{array}$ \\
\hline Enigmas & $\begin{array}{c}\text { Birkinshaw e Gibson (2004); O’Reilly e } \\
\text { Tushman (2004) }\end{array}$ & $\begin{array}{l}\text { O fracasso em alcançar inovações radicais enquanto } \\
\text { faz melhorias constantes para um negócio existente } \\
\text { é tão fascinante que se tornou um campo de } \\
\text { batalha do pensamento de gestão. Durante décadas, } \\
\text { os estudiosos têm desenvolvido teorias para } \\
\text { explicar o ENIGMA, além de conselhos sobre } \\
\text { como resolvê-lo (O’REILLY; TUSHMAN, 2004, } \\
\text { p. 1) }\end{array}$ \\
\hline Dilema & $\begin{array}{l}\text { Benner e Tushman (2003); Cao et al. } \\
\text { (2009); Chandrasekaran et al. (2012); } \\
\text { Duncan (1976); Luzon e Pasola (2011) }\end{array}$ & $\begin{array}{l}\text { Nenhum estudo forneceu uma solução para o } \\
\text { DILEMA de exploração e explotação através da } \\
\text { ambidestria (LUZON; PASOLA, 2011, p. 928) }\end{array}$ \\
\hline Paradoxo & $\begin{array}{l}\text { Andriopoulos e Lewis (2009, 2010); Bierly } \\
\text { e Daly, (2007); O’Reilly e Tushman (2008); } \\
\text { Smith e Tushman (2005); Tiwana (2008) }\end{array}$ & $\begin{array}{c}\text { Porque as rotinas, processos e habilidades } \\
\text { necessárias para a explotação são } \\
\text { fundamentalmente diferentes do que as necessárias } \\
\text { para a exploração, nós rotulamos esses recursos } \\
\text { PARADOXAIS como ambidestria (O'REILLY; } \\
\text { TUSHMAN, 2008, p. 188). }\end{array}$ \\
\hline
\end{tabular}

Fonte: Karrer e Fleck (2015, p. 371) 
Concluindo este caso para ensino, é importante destacar que, apesar das pesquisas sobre ambidestria estarem avançando, os autores apresentam conceitos, ideias, características e opiniões, que muitas vezes, são divergentes sobre este tema. Alguns autores defendem a ambidestria a partir de ações simultâneas de inovação exploratória e explotatória. Entretanto, existem, também, discussões teóricas sobre o fato de não ser possível coexistirem estruturas duais (por conta dos escassos recursos) que não priorizem um tipo de inovação em detrimento do outro, avançando na discussão sobre a possibilidade e necessidade de combinações múltiplas de estratégias organizacionais ambidestras.

\section{Referências}

BENNER, M. J.; TUSHMAN, M. L. Exploitation, exploration, and process management: The productivity dilemma revisited. Academy of management review, v. 28, n. 2, p. 238-256, 2003.

DUNCAN, R. B. The ambidextrous organization: Designing dual structures for innovation. The management of organization, v. 1, p. 167-188, 1974.

DURISIN, B.; TODOROVA, G. The Ambidextrous Organization: Managing Simultaneously Incremental and Radical Innovation?. Sda Bocconi, Working Paper, n. 96 , set. 2003.

GUPTA, A. K.; SMITH, K. G.; SHALLEY, C. E. The interplay between exploration and exploitation. Academy of Management Journal, v. 49, n. 4, p. 693706, 2006.

HE, Z.; WONG, P. K. Exploration vs. exploitation: An empirical test of the ambidexterity hypothesis. Organization Science, n. 15, p. 481-494, 2004.

KARRER, D.; FLECK, D. Organizing for ambidexterity: a paradox-based typology of ambidexterity-related organizational states. Brazilian Administration Review. v. 12, n. 4, 365-383, 2015.

MARCH, J. G. Exploration and exploitation in organizational learning. Organization Science, n. 2, p. $71-87,1991$.

PURVEE, A.; ENKHTUVSHIN, D.

Transformational Leadership and Managers' Ambidexterity: Mediating Role of Environmental
Dynamism. International Journal of Innovation, Management and Technology. v. 5, n. 6, 434-437, 2014.

RAMACHANDRAN, I. Increasing firm performance through a reassessment of appropriate balance: impact of tmt composition on ambidexterity configurations. 2012. Dissertation (Department of Management), The University Of Texas, San Antonio, USA.

RAMOS, H. R.; MATOS, H. T. Organizational context as elemento of the development ambidexterity in the small business. International Journal of Innovation. v. 3, n. 1, 35-47, 2015.

SCOT'T, N. Ambidextrous strategies and innovation priorities: adequately priming the pump for continual innovation. Technology Innovation Management Review. v. 4, n. 7, 44-51, 2014.

SILVEIRA-MARTINS, E.; ROSSETTO, C. R. Ambidestria organizacional - exploração e explotação: um estudo bibliométrico nas bases de dados internacionais. Revista Gestão Organizacional. v. 7, n. 2, 15-29, 2014.

SILVEIRA-MARTINS, E.; ROSSETTOO, C. R.; AÑAÑA, E. S. Ambidestria, exploração ou explotação e seus efeitos no desempenho organizacional de vinícolas brasileiras. Revista em Agronegócios e Meio Ambiente. v. 7, n. 3, 707-732, 2014.

SILVEIRA-MARTINS, E.; ROSSETTTO, C. R.; LIMA, N. C.; PENEDO, A. S. T. Comportamento estratégico e ambidestria: um estudo aplicado junto às empresas vinícolas brasileiras. Revista Brasileira de Gestão e Negócios. v. 16, n. 52, 392-415, 2014.

SILVEIRA-MARTINS, E.; VAZ, C. S. Orientação empreendedora e sua associação com as capacidades dinâmicas: um estudo em agroindústrias gaúchas. Revista em Agronegócios e Meio Ambiente. no prelo. 2016.

TINOCO, J. K. Double dealing: the influences of diverse business processes on organizational ambidexterity. Academy of Strategic Management Journal. v. 13, n. 2, 87-110, 2014.

TUSHMAN, M. L.; O'REILLY, C. A. Ambidextrous organizations: Managing evolutionary and revolutionary change. California Management Review, v. 38, n. 4, p. 8-30, 1996. 